\title{
Study on antimony cake as a technogenic raw material for the production of antimony oxides
}

\author{
Zarlyk Maimekov ${ }^{1}$, Zhyldyz Tunguchbekova ${ }^{2}$, Kubat Kemelov*1, Uran Maimekov ${ }^{3}$, Damira \\ Sambaeva $^{2}$
}

${ }^{1}$ Kyrgyz-Turkish Manas University, Engineering Faculty, Department of Environmental Engineering, Bishkek, Kyrgyz Republic, kubat.kemelov@manas.edu.kg, ORCID:0000-0001-7375-6325

${ }^{2}$ Kyrgyz State University of Geology, Mining and Natural Resources Development, Bishkek, Kyrgyz Republic

${ }^{3}$ Moscow Institute of Physics and Technology, Dolgoprudny, Russia

\section{A B S T R A C T}

In the process of hydrometallurgical and pyrometallurgical production of antimony at the Kadamzhai antimony plant of the Kyrgyz Republic, large-tonnage waste was generated: tailing sand, matte, slag, off-balance ore, cakes, furnace fragments, and electrolytes in salt warehouses. The waste cake is poorly studied; accordingly, the elemental and phase compositions of antimony cake have not been established. In this regard, it was noted that antimony in the cake occurs in the form of calcium antimonate and antimony hydroxide. The content of antimony in the mine tailings cakes is from 3.53 to $4.4 \%$, with a high content of iron $(27.5 \%)$ and sodium $(8.86 \%)$. Based on the established elemental and phase compositions, a chemical matrix of antimony cake was compiled. The equilibrium compositions were calculated and the concentration distribution of the main elements of the cake ( $\mathrm{Fe}, \mathrm{Na}, \mathrm{Si}, \mathrm{Sb})$ and their compounds in the gas phase was found depending on the temperature of the destruction of the solid phase. It was found that condensed antimony oxides are formed in the range of 1098 - $1348 \mathrm{~K}$. Taking into account the range of temperatures for decomposition of the solid phase, a two-stage smelting of antimony cake is proposed (melting and cupellation). The conversion of antimony cake sulfides from the gas phase into a solution was carried out based on a study of the system: antimony sulfide- manganese (IV) dioxide- sulfuric acid - sodium chloride. The $\mathrm{pH}$ value and the redox potential (Eh) of the solution were calculated. It is noted that the sulfur compounds of antimony from the cake are converted to antimony oxychloride with the formation of antimony (III) oxide in an alkaline medium. The use of sodium chloride as a chlorinating agent of antimony sulfur compounds does not lead to the formation of toxic phosgene and hydrogen sulfide; in the solid phase, elemental sulfur is released, which is important for minimizing the technogenic load of pollutants on the environment.

\section{ART ICLE INFO}

\section{Research article}

Received: 6.04.2021

Accepted: 21.06.2021

Keywords:

Kadamzhai antimony,

antimony cake,

modeling,

complex system,

waste,

environment

${ }^{*}$ Corresponding author

\section{Introduction}

Antimony cake is an insoluble solid obtained in the process of extracting valuable components from ore. Currently, considerable attention is paid to the environmental problems of the chemistry and technology of antimony and its compounds [1-17]; environmental pollution with antimony wastes [1, 13, 16]; behavior of antimony in swampy groundwater [2]; antimony waste and dust emissions during smelting process [3, 14, 17]; environmental risks [4] and removal of antimony in water by electrocoagulation [5]; accumulation and transformation of antimony in the environment [5]; removal of antimony (III) by adsorption using carbon nanotubes and bimetallic oxide polymer anion exchange resin, adsorption of $\mathrm{Sb}(\mathrm{V})$ on the surface of binitite and ferrihydrite; geochemistry of antimony mobility and transport [6-9, 11].

It is noted that the cakes of the tailing dump are multicomponent and occur in the form of a technogenic formation. Environmental problems of industrial waste, including the production of antimony, are very important [10]. In particular, the assessment of pollution in the area of antimony mining, prevention of the process of waterlogging of spent electrolytes and their seepage into groundwater, reduction of the destruction of antimony by plants and soil of systematic scientific and practical research. In this study, to predict the processes of chemical transformation of the solid 
phase and the formation of antimony oxide (III), the physicochemical principles of the destruction of waste antimony cake in a gas-liquid oxidizing medium were considered based on experimental analyzes of antimony cake examples of the Kadamzhai antimony plant (KAP).

\section{Material and methods}

The main elemental composition of the antimony cake, formed in the KAP, was determined by an atomic absorption spectrometer AAnalyst 800 (Perkin Elmer, USA). An ICP OES Optima 7000 optical emission spectrometer with inductively coupled plasma was used to detect small impurities of individual elements. The processing of the diffraction pattern and the calculation of interplanar distances were carried out using the EVA software. Sample decoding and the search for phases were performed with "Search / Match" program using the PDF-2 powder diffractometric database (Fig. 1) [18]. The study of the process of oxidation and destruction of antimony cake in oxygen at different temperatures was carried out by the method of thermodynamic modeling of the system at maximum entropy using the "Terra" program [19]. Methodical calculation algorithm equilibrium of formation of gaseous, condensed substances, electrically neutral and ionized components, pure phases, and their solutions. The equilibrium of the studied system was achieved at the maximum entropy relative to the thermodynamic degrees of freedom (M, T, P). Specific volume (V) and internal energy (U) are related to the concentration of components in the filter cake, as well as temperature and pressure. The pressure value and the temperature limits of the decomposition of the solid phase were given. The elemental composition of the cake was experimentally determined per 1 $\mathrm{kg}$ of the carrier $(\mathrm{mol} / \mathrm{kg})$.

It is noted that antimony cake consists of complex independent components. The destruction of the cake in the gas phase proceeds with the formation of individual low molecular weight components, atomic and ionic particles. Therefore, the phase transition of the components was taken as a chemical reaction, and the number of independent reactions was equal to the number of components. In this case, the reactions were chosen as independent reactions, in which the distribution of the concentrations of individual independent elements ( $\mathrm{Fe}, \mathrm{O}, \mathrm{Si}, \mathrm{S}, \mathrm{Na}, \mathrm{Ca}, \mathrm{Sb}, \mathrm{H}, \mathrm{Al}, \mathrm{Mg}$ ) was taken into account. The physicochemical and thermodynamic parameters of the system antimony cake oxygen were calculated at $\mathrm{P}=0.1 \mathrm{MPa}, \mathrm{T}=298-3098 \mathrm{~K}$ (with a step of $200 \mathrm{~K}$ ). The calculation of entropy from the values of $\Delta \mathrm{S}, \Delta \mathrm{H}, \mathrm{Cp}, \mathrm{T}$, made it possible to determine the changes in the Gibbs energy $\left(\Delta \mathrm{G}_{\mathrm{T}}=\Delta \mathrm{H}_{\mathrm{T}}-\mathrm{T} \Delta \mathrm{S}_{\mathrm{T}}\right)$, and the transition from $\Delta \mathrm{GT}$ to the equilibrium constant $(\mathrm{K})$ was carried out according to the formula $\Delta \mathrm{G}=-\mathrm{RT} \operatorname{lnK}$ [19].

\section{Results and discussion}

In the scope of this study, the elemental and phase compositions of the KAP antimony cake were examined (Table 1, Figure 1). As the results showed, the content of antimony in the mine tailings cakes ranged from 3.53 to $4.42 \%$. Besides, high levels of iron $(27.5 \%)$ and sodium $(8.86 \%)$ were detected.

The phase composition of antimony cake, obtained by semiquantitative X-ray phase analysis, showed (Fig. 1) that the main minerals are hematite - cristobalite $\left(\mathrm{Fe}_{2} \mathrm{O}_{3} \mathrm{SiO}_{2}\right)$, pyrites $\left(\mathrm{FeS}_{2}\right)$, magnetite $\left(\mathrm{Fe}_{3} \mathrm{O}_{4}\right)$, hexasodium iron tetrasulfate $\mathrm{Na}_{6} \mathrm{Fe}\left(\mathrm{SO}_{4}\right)_{4}$, pyrrhotite $\left(\mathrm{Fe}_{1.05} \mathrm{~S}_{0.95}\right)$, calcium antimonate $\mathrm{CaNaSb}_{2} \mathrm{O}_{6}(\mathrm{OH})$-calcium oxide $\mathrm{CaO}$, antimony hydroxide $\mathrm{SbSb}_{2} \mathrm{O}_{6}(\mathrm{OH})$, sodium aluminate $\left(\mathrm{NaAlO}_{2}\right)$, periclase $(\mathrm{MgO})$; the composition of the gas phase is $100 \%$ oxygen.

Table 1. Elemental composition of antimony cake of the KAP (in ppm) according to the atomic absorption spectrometer

\begin{tabular}{cccc}
\hline $\begin{array}{c}\text { Sample } \\
\text { cake }\end{array}$ & $\begin{array}{c}\text { Concentration, } \\
\text { ppm }\end{array}$ & $\begin{array}{c}\text { Sample } \\
\text { cake }\end{array}$ & $\begin{array}{c}\text { Concentration, } \\
\text { ppm }\end{array}$ \\
\hline $\mathbf{A s}$ & 10256.5 & $\mathbf{M o}$ & 0.9 \\
$\mathbf{C d}$ & 29 & $\mathbf{N i}$ & 94 \\
$\mathbf{C r}$ & 84 & $\mathbf{P b}$ & 8292.5 \\
$\mathbf{C u}$ & 893.5 & $\mathbf{Z n}$ & 3294.5 \\
$\mathbf{H g}$ & 4.5 & $\mathbf{S b}$ & 44221 \\
\hline
\end{tabular}

Antimony in antimony cake occurs in the form of calcium antimonate $\mathrm{CaNaSb}_{2} \mathrm{O}_{6}(\mathrm{OH})$ and antimony hydroxide $\mathrm{SbSb}_{2} \mathrm{O}_{6}(\mathrm{OH})$. Based on the experimentally found elemental and phase compositions of antimony cake (Table 1 and Fig. 1 ), the chemical matrix of the antimony cake was compiled (in \%): $\mathrm{Fe}_{2} \mathrm{O}_{3} \mathrm{SiO}_{2}$ (25.5) - $\mathrm{FeS}_{2}$ (21.2) - $\mathrm{Fe}_{3} \mathrm{O}_{4}$ (12.4) $\mathrm{Na}_{6} \mathrm{Fe}\left(\mathrm{SO}_{4}\right)_{4}(12.1)-\mathrm{Fe}_{1.05} \mathrm{~S}_{0.95}$ (11) - $\mathrm{CaNaSb}_{2} \mathrm{O}_{6} \mathrm{OH}(8.2)$, $\mathrm{CaO}$ (1.67) - $\mathrm{SbSb}_{2} \mathrm{O}_{6} \mathrm{OH}(5.4)-\mathrm{NaAlO}_{2}$ (2.65) - $\mathrm{MgO}(0.13)$. Taking into account the chemical matrix of antimony cake, thermodynamic modeling of the process of destruction of antimony cake in an oxygen medium was carried out, and temperature ranges of the formation and chemical transformation of antimony-containing components and particles in the gas phase were revealed. 


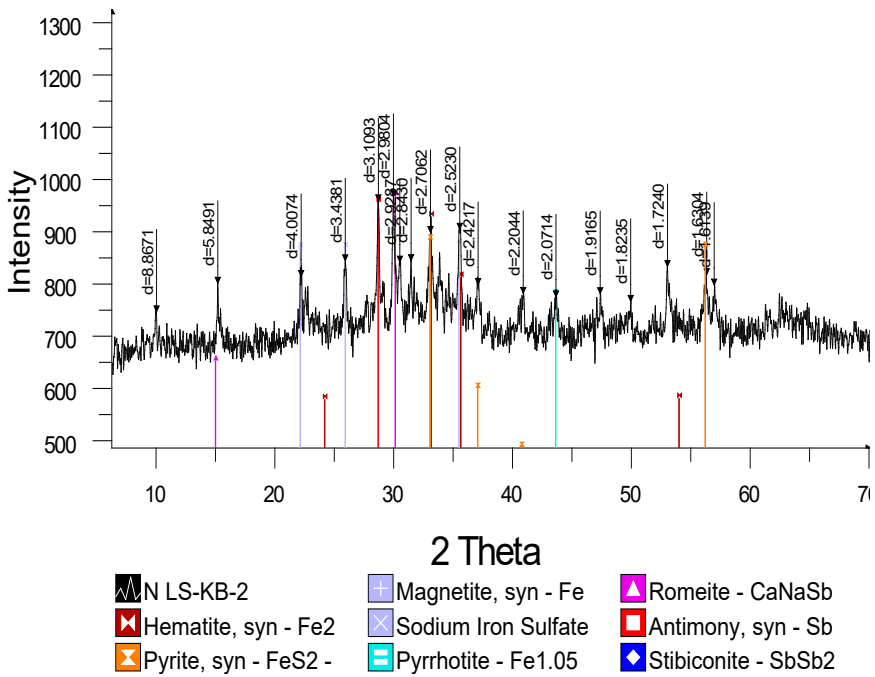

Figure 1. Diffractogram of the KAP antimony cake

The calculated partial pressure of oxygen in the antimony cake - oxygen system was $0.084 \mathrm{MPa}$ at $298 \mathrm{~K} ; 0.084 \mathrm{MPa}$ at $848 \mathrm{~K}$; $0.084 \mathrm{MPa}$ at $1448 \mathrm{~K} ; 0.078 \mathrm{MPa}$ at $2298 \mathrm{~K}$ and $0.060 \mathrm{MPa}$ at
$3048 \mathrm{~K}$, that is, in the range of $298-1448 \mathrm{~K}, \mathrm{P}_{\mathrm{O} 2}$ was equal to $0.084 \mathrm{MPa}$; molar concentration of oxygen in the gas phase at various temperatures was as follows: $10.88 \mathrm{~mol} / \mathrm{kg}$ at $298 \mathrm{~K}$; $10.88 \mathrm{~mol} / \mathrm{kg}$ at $848 \mathrm{~K} ; 10.88 \mathrm{~mol} / \mathrm{kg}$ at $1448 \mathrm{~K}$, i.e in the temperature range of $298-1448 \mathrm{~K} \mathrm{C} \mathrm{C}_{\mathrm{O}}$ is $10.88 \mathrm{~mol} / \mathrm{kg}$, and $\mathrm{P}_{\mathrm{O} 2}$ is $0.084 \mathrm{MPa}$ (constant), which reflects the conditions of existence of the studied system. Thus, further calculations were carried out at a pressure of $0.1 \mathrm{MPa}$. It should be noted here that the temperature range from 298 to $3100 \mathrm{~K}$ (Fig. 2) in the computational experiments was selected based on the temperature of combustion, decomposition, and melting of the main components of the antimony cake. Also, the formation of active particles and ions in the gas phase (Fe, $\mathrm{Tm}=1812 \mathrm{~K}$; $\mathrm{Na}, \mathrm{Tm}=371 \mathrm{~K} ; \mathrm{Sb}, \mathrm{Tm}=904 \mathrm{~K} ; \mathrm{Si}, \mathrm{Tm}=1688 \mathrm{~K} ; \mathrm{Ca}, \mathrm{Tm}$ $=1115 \mathrm{~K} ; \mathrm{Al}, \mathrm{Tm}=933 \mathrm{~K} ; \mathrm{Mg}, \mathrm{Tm}=923 \mathrm{~K}$, Tm is a melting temperature) were taken into consideration.

During the high-temperature decomposition of the antimony cake in the gas phase, the following components were formed: $\mathrm{Sb}, \mathrm{SbO}, \mathrm{SbH}, \mathrm{Sb}_{4} \mathrm{O}_{6}, \mathrm{Sb}_{2} \mathrm{O} 4$ (c), $\mathrm{Sb}_{2} \mathrm{O}_{5}(\mathrm{c}), \mathrm{Sb}_{2}, \mathrm{Sb}_{3}, \mathrm{Sb}_{4}, \mathrm{Sb}-$ , $\mathrm{SbO}_{2-}, \mathrm{SbS}, \mathrm{SbO}_{2}$ (Table 2).

Table 2. Equilibrium compositions and concentrations of Sb-containing components and cake particles at various temperatures of the destruction of the solid phase

\begin{tabular}{|c|c|c|c|c|}
\hline \multirow{2}{*}{$\begin{array}{l}\mathrm{C}, \\
\mathrm{mol} / \mathrm{kg}\end{array}$} & \multicolumn{4}{|c|}{$\mathbf{T}, \mathbf{K}$} \\
\hline & 1648 & 2048 & 2348 & 2698 \\
\hline Sb & $4 \cdot 10^{-7}$ & $1 \cdot 10^{-3}$ & $1 \cdot 10^{-2}$ & $3.1 \cdot 10^{-2}$ \\
\hline $\mathbf{S b}_{2}$ & $6 \cdot 10^{-11}$ & $5 \cdot 10^{-6}$ & $5 \cdot 10^{-1}$ & $6 \cdot 10^{-5}$ \\
\hline $\mathrm{Sb}_{3}$ & - & $1 \cdot 10^{-9}$ & $2 \cdot 10^{-8}$ & $2 \cdot 10^{-8}$ \\
\hline $\mathrm{Sb}_{4}$ & \multicolumn{4}{|c|}{$1 \cdot 10^{-12}(2098 \mathrm{~K})-1 \cdot 10^{-12}(2648 \mathrm{~K})$} \\
\hline $\mathbf{S b}^{-}$ & - & $3 \cdot 10^{-10}$ & $5 \cdot 10^{-8}$ & $6 \cdot 10^{-7}$ \\
\hline $\mathrm{SbO}_{2}^{-}$ & $6 \cdot 10^{-10}$ & $2 \cdot 10^{-6}$ & $2 \cdot 10^{-5}$ & $1 \cdot 10^{-5}$ \\
\hline SbO & $6 \cdot 10^{-4}$ & $1.4 \cdot 10^{-1}$ & $3.5 \cdot 10^{-1}$ & $3.2 \cdot 10^{-1}$ \\
\hline SbH & $6 \cdot 10^{-9}$ & $8 \cdot 10^{-5}$ & $1 \cdot 10^{-3}$ & $1.1 \cdot 10^{-2}$ \\
\hline SbS & - & $1 \cdot 10^{-8}$ & $7 \cdot 10^{-7}$ & $9 \cdot 10^{-6}$ \\
\hline $\mathrm{SbO}_{2}$ & $5 \cdot 10^{-7}$ & $9 \cdot 10^{-5}$ & $2 \cdot 10^{-4}$ & $2 \cdot 10^{-4}$ \\
\hline $\mathrm{Sb}_{4} \mathrm{O}_{6}$ & $9 \cdot 10^{-2}$ & $5.6 \cdot 10^{-2}$ & $2 \cdot 10^{-5}$ & $6 \cdot 10^{-10}$ \\
\hline $\mathrm{Sb}_{2} \mathrm{O}_{4}(\mathrm{c})$ & \multicolumn{4}{|c|}{$1.82 \cdot 10^{-1}(1098 \mathrm{~K})-3.64 \cdot 10^{-2}(1348 \mathrm{~K})$} \\
\hline $\mathrm{Sb}_{2} \mathrm{O}_{5}(\mathrm{c})$ & \multicolumn{4}{|c|}{$1.82 \cdot 10^{-1}(1048 \mathrm{~K})$} \\
\hline
\end{tabular}

Figure 2 shows the equilibrium compositions and concentrations of the main antimony-containing components, including the condensed phases of $\mathrm{Sb}_{2} \mathrm{O}_{4}(\mathrm{c}), \mathrm{Sb}_{2} \mathrm{O}_{5}$ (c) during the decomposition of antimony cake. Here, the concentration of the condensed phase was in the range of $10-2 \mathrm{~mol} / \mathrm{kg}$. and for low molecular weight particles and ions, such as $\mathrm{Sb}_{2}, \mathrm{Sb}_{3}$, $\mathrm{Sb}_{4}, \mathrm{Sb}-, \mathrm{SbO}_{2-}$, the concentration ranged from $10^{-12}$ to $10^{-4}$ $\mathrm{mol} / \mathrm{kg}$ (Table 2). 


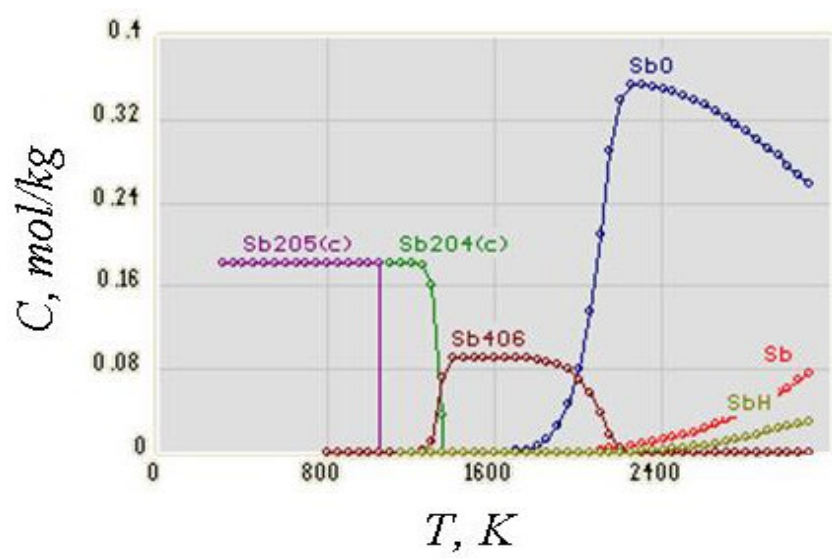

Figure 2. Concentrations of Sb containing components and particles in the gas phase depending on the decomposition temperature of the cake

The experimental results show that some condensed substances like $\mathrm{Sb}_{2} \mathrm{O}_{4}(\mathrm{c}), \mathrm{Sb}_{2} \mathrm{O}_{5}$ (c) can be formed at a temperature of $1048 \mathrm{~K}$ (Table 2), and particles $\left(\mathrm{Sb}, \mathrm{Sb}_{2}, \mathrm{Sb}_{3}\right.$, $\left.\mathrm{Sb}_{4}\right)$ and ions $\left(\mathrm{Sb}^{-}, \mathrm{SbO}_{2}^{-}\right)$are formed at high temperatures up to $3000 \mathrm{~K}$ (Fig. 2, Table 2). Table 2 shows the maximum temperature that needs to be reached in the process of Sb-cake destruction equals $1812 \mathrm{~K}$. Thus, the chemical transformation of antimony-containing condensed substances proceeds at1348 K. As mentioned above, the formation of atomicmolecular $\left(\mathrm{Sb}, \mathrm{Sb}_{2}, \mathrm{Sb}_{3}, \mathrm{Sb}_{4}\right)$ and ionic particles $\left(\mathrm{Sb}^{-}, \mathrm{SbO}_{2}^{-}\right)$ in the gas phase were detected at higher temperatures (Fig. 2).

Table 2 shows only negative ions of antimony, while the results of decomposition of the antimony cake at high temperatures showed the formation of negative and positive ions $(\mathrm{mol} / \mathrm{kg})$, for example, at $2698 \mathrm{~K}: \mathrm{O}^{-}=0,25 \cdot 10^{-4}, \mathrm{O}_{2}{ }^{-}=$ $0,23 \cdot 10^{-4}, \mathrm{H}^{-}=0,73 \cdot 10^{-8}, \mathrm{OH}^{-}=0,55 \cdot 10^{-5}, \mathrm{HO}_{2}{ }^{-}=0,18 \cdot 10^{-7}, \mathrm{~S}^{-}=$ $0,14 \cdot 10^{-6}, \mathrm{~S}_{2}^{-}=0,74 \cdot 10^{-10}, \mathrm{SO}^{-}=0,12 \cdot 10^{-5}, \mathrm{SO}_{2}^{-}=0,12 \cdot 10^{-3}, \mathrm{SH}^{-}=$ $0,17 \cdot 10^{-8}, \mathrm{Sb}^{-}=0,56 \cdot 10^{-6}, \mathrm{SbO}_{2}^{--}=0,15 \cdot 10^{-4}, \mathrm{Al}^{+}=0,12 \cdot 10^{-11}$, $\mathrm{AlO}^{-}=0,40 \cdot 10^{-5}, \mathrm{AlO}_{2}^{-}=0,53 \cdot 10^{-5,} \mathrm{Fe}^{+}=0,52 \cdot 10^{-9}, \mathrm{Mg}^{+}=$ $0,46 \cdot 10^{-10}, \mathrm{Ca}^{+}=0,31 \cdot 10^{-10}, \mathrm{CaO}^{+}=0,65 \cdot 10^{-10}, \mathrm{CaOH}^{+}=0,37 \cdot 10^{-}$ ${ }^{9}, \mathrm{Na}^{+}=0,76 \cdot 10^{-3}, \mathrm{Na}_{2} \mathrm{O}^{+}=0,9 \cdot 10^{-7}$.

It was found that during the destruction of the antimony cake of the KAP condensed antimony oxides are formed in the range of 1098-1348 $\mathrm{K}$ (Table 2). Based on the range of formation and transformation of the condensed phase, a twostage smelting of antimony cake was proposed. A sample of antimony cake was placed into a ball mill. Then, the crushed sample was subjected to batching ( $70 \%$ glut $/ \mathrm{PbO} /+20 \%$ soda $+10 \%$ borax) in the cake - the ratio of the mixture was set $1: 3$. The mixture was mixed with flour $(1-3 \mathrm{~g})$ and silver nitrate $(0.2 \mathrm{ml})$. Flour was used to stabilize an acidic medium (borax is used in an alkaline medium); lead oxide was used to produce a lead alloy (crude lead), and silver nitrate was used to absorb noble metals from the cake. The resulting mixture was mixed until a homogeneous mixture was obtained. This mixture was loaded into fireclay crucibles. In the furnace, the mixture started melting at the temperature of $1328-1473 \mathrm{~K}$ (45-50 min.). At the initial stage of smelting (30 $\mathrm{min})$, the sample melted at a temperature of $1203-1303 \mathrm{~K}$.

At the initial stage of melting $(30 \mathrm{~min})$ at a temperature of 1203-1303 K, the sample melted with the formation of a lead melt and the release of gaseous products (sulfide sublimation). Within 20 minutes, drops of liquid lead melt completely covered the antimony cake. After 50 minutes, the multicomponent melt was poured into cast-iron molds and the latter cooled in the air (10-15 minutes). In primary smelting, many metals and their impurities, including precious ones, are absorbed by the lead-silver collector. Thus, a lead alloy was formed - crude lead, which was covered with quartz slag. This quartz slag was cleaned off from the surface of the lead alloy with a hammer. At the second stage of melting (cupellation), the furnace was heated to a temperature of $1253 \mathrm{~K}$. For this, the crude lead was preheated $(1173 \mathrm{~K})$ for 10-15 minutes (the melting point of lead is $600 \mathrm{~K}$ ). During the cupelling process, the white finely porous surface of the crucible turns yellow due to the sorption of some alkaline, alkaline-earth, and other metals in the cake, including lead (at temperatures below 800 $\mathrm{K})$. At the bottom of some crucibles, an alloy of antimony with metal impurities (Ag) remained, which melt above $800 \mathrm{~K}$ (melting temperatures of antimony are equal to $904 \mathrm{~K}$ ). The silver-antimony glance glares brightly when the last particles of lead are removed from its surface. It means the end of the cupellation process of the lead alloy. To transfer the sulfide sublimate of antimony cake to the solution, the following system was studied: antimony sulfide - manganese dioxide (IV) - sulfuric acid - sodium chloride within the temperature ranged from $288 \mathrm{~K}$ to $358 \mathrm{~K}$ and pressure of $\mathrm{P}=10^{5} \mathrm{~Pa}$ with the minimal Gibbs energy based on the program "Selector" [20].

The values of $\mathrm{pH}$ and $\mathrm{Eh}$ of solution in a wide temperature ranges $(288 \mathrm{~K}, \mathrm{pH}=2.05, \mathrm{Eh}=1.14 \mathrm{~V} ; 298 \mathrm{~K}, \mathrm{pH}=1.96$, $\mathrm{Eh}=1.15 \mathrm{~V} ; 318 \mathrm{~K}, \mathrm{pH}=2.02, \mathrm{Eh}=1.13 \mathrm{~V} ; 338 \mathrm{~K}, \mathrm{pH}=2.14$, $\mathrm{Eh}=1.12 \mathrm{~V} ; 358 \mathrm{~K}, \mathrm{pH}=2.3, \mathrm{Eh}=1.1 \mathrm{~V}$ ) were calculated. The $\mathrm{pH}$ of the solution ranged between 1.96 and 2.3; the ionic strength was equal to 10 , the oxidizing medium was greater than zero (Eh>0). It was noticed that antimony compounds (sublimates of sulfur of the type: SbS, Sb2S3) from the cake pass into antimony (III) chloride according to the following reaction [14]:

$$
\begin{gathered}
\mathrm{Sb}_{2} \mathrm{~S}_{3}+3 \mathrm{MnO}_{2}+6 \mathrm{H}_{2} \mathrm{SO}_{4}+12 \mathrm{NaCl}=2 \mathrm{SbCl}_{3}+3 \mathrm{MnCl}_{2}+6 \mathrm{Na}_{2} \mathrm{SO} \\
{ }_{4}+3 \mathrm{~S} \downarrow+6 \mathrm{H}_{2} \mathrm{O} .
\end{gathered}
$$

Antimony trioxide can be obtained by hydrolysis of antimony chloride followed by dehydration of the resulting methantimonic acid.

$$
\begin{gathered}
2 \mathrm{SbCl}_{3}+3 \mathrm{Na}_{2} \mathrm{CO}_{3}+\mathrm{H}_{2} \mathrm{O}=2 \mathrm{HSbO}_{2}+3 \mathrm{CO}_{2}+6 \mathrm{NaCl} \\
2 \mathrm{HSbO}_{2}=\mathrm{Sb}_{2} \mathrm{O}_{3}+\mathrm{H}_{2} \mathrm{O} .
\end{gathered}
$$


A solution of antimony trichloride in a mixture of $\mathrm{HCl}$ and water was slowly poured into a boiling solution of $\mathrm{Na}_{2} \mathrm{CO}_{3}$ $10 \mathrm{H}_{2} \mathrm{O}$. The mixture was boiled until $\mathrm{CO}_{2}$ is completely removed, then the liquid was carefully decanted. The precipitate was sucked off, washed with hot water until the complete absence of chlorine ions in the washings, and dried at $150{ }^{\circ} \mathrm{C}$ until constant weight $(80 \%$ yield). Antimony pentoxide was obtained through the interaction of $\mathrm{Sb}_{2} \mathrm{O}_{3}$ and oxygen.

The results of the research showed that the $\mathrm{pH}$ value of the working solution at $298 \mathrm{~K}$ was equal to 1.96 , and $\mathrm{Eh}=1.15$ $\mathrm{V}$, which means that the medium was acidic. When sodium chloride was used, hydrogen chloride was formed as a chlorinating agent during the intramolecular chemical transformation of the starting components. No toxic phosgene and hydrogen sulfide were formed in the reaction medium; elemental sulfur was deposited, which plays a vital role in minimizing technogenic loads of pollutants on the environment.

\section{Conclusions}

In antimony cake, antimony occurs in the form of calcium antimonate and antimony hydroxide. Taking into account the temperature of the formation of condensed antimony oxides (1098-1348K), in the study, a two-stage smelting of antimony cake was performed (smelting and cupellation). Acid sublimates of antimony cake were placed in a mixture of manganese dioxide (IV), sulfuric acid, and sodium chloride solute to gradually obtain antimony chloride (III) and antimony chloroxide ( $\mathrm{SbOCl})$. Emission of antimony oxide (III) was observed during the interaction of antimony oxychloride with ammonium hydroxide. The use of sodium chloride as a chlorinating agent eliminated the possibility of the formation of toxic phosgene and hydrogen sulfide in the reaction medium.

\section{References}

[1]. He M.C., Wang X.Q., Wu F.C., Fu Z.Y., "Antimony pollution in China", Science of the Total Environment, 421-422, (2012), 41-50.

[2]. Wan X.M., Tandy S., Hockmann K., Schulin R., "Changes in Sb speciation with waterlogging of shooting range soils and impacts on plant uptake", Environmental Pollution, 172, (2013), 53-60.

[3]. Xuejun G., Kunpeng W., Mengchang H., Ziwei L., Hailin Y., Sisi L., "Antimony smelting process generating solid wastes and dust: Characterization and leaching behaviors", Journal of Environmental Sciences, 26, (2014), 1549-1556.
[4]. Wilson S. C., Lockwood P. V., Ashley P. M., Tighe M., "The chemistry and behavior of antimony in the soil environment with comparisons to arsenic: A critical review", Environmental Pollution, 158, (2010), 11691181.

[5]. Yang H., He M., Wang X., "Concentration and speciation of antimony and arsenic in soil profiles around the world's largest antimony metallurgical area in China", Environmental Geochemistry and Health, 37(1), (2014), 21-33.

[6]. Zhu J., Wu F., Pan X., Guo J., "Removal of Antimony from Antimony Mine Flotation Wastewater by Electrocoagulation With Aluminum Electrodes", Journal of Environmental Sciences, 23. (7), (2011), 1066-1071.

[7]. Miao Y., Han F., Pan B., Niu Y., Nie G., Lv L., "Antimony (V) removal from water by hydrated ferric oxides supported by calcite sand and polymeric anion exchanger", Environmental Sciences, 26, (2014), 307314.

[8]. Li X., Dou X., Li J., “Antimony(V) removal from water by iron-zirconium bimetal oxide: Performance and mechanism", Journal of Environmental Sciences, 24(7), (2012),1197-1203.

[9]. Qi P.F., Pichler T., "Sequential and simultaneous adsorption of $\mathrm{Sb}$ (III) and $\mathrm{Sb}(\mathrm{V})$ on ferrihydrite: Implications for oxidation and competition", Chemosphere, 145, (2016), 55-60.

[10]. Indika H., Meththika V., Jochen B., "Antimony as a global dilemma: Geochemistry, mobility, fate and transport", Environmental Pollution, 223, (2017), 545559.

[11]. Wang H.W., Li X.Y., Li W.H., Sun Y.L., "Effects of $\mathrm{pH}$ and complexing agents on $\mathrm{Sb}(\mathrm{V})$ adsorption onto binessite and ferrihydrite surface", Environmental Science, 38, (2017), 180-187.

[12]. Bolshakov L.A., Salimzhanova E.V., Yuryev A.I., "Studies on the possibility of reducing the content of non-ferrous metals in mine tailings ferrous cakes", Ore and metals, 6, (2013), 65 - 68.

[13]. Maymekov Z.K., Sambaeva D.A., Shabdanova E.A., "Ecological aspects of antimony production and some ways to minimize the formation of man-made waste in them”, KNAU Bulletin, 2 (29), (2013), 227-228. 
[14]. Solozhenkin P.M., Zinchenko Z.A., "Enrichment of antimony ores", Nauka, 1985, 180

[15]. Ochurool A.P., Shoeva T.N., The study of the composition and properties of the cake, Collected Works of Tuva State University, 2015, 198-199.

[16]. Kozhonov A.K., Nogayeva K.A., Molmakova M.S., "Review and classification of industrial wastes from ore deposits of the Kyrgyz Republic", News KSTU. I.Razzakov, 3(39), (2016), 259 - 263.

[17]. Akimenko D.O., Pashkevich M.A., "Estimates of the influence of the cake mine tailings on the components of the environment and the possibility of its full processing, as a technogenic deposit of CJSC ZSU", Mountain science and technology, 8, (2011) 3-8.
[18]. Knyazev A.V., Suleymanov E.V., Fundamentals of Xray phase analysis. Study guide. Nizhny Novgorod, 2005,23

[19]. Trusov B.G., Badrak S.A., Turov V.P., Baryshevskaya I.I., "Automated system of thermodynamic data and calculations of equilibrium states", Mathematical methods of chemical thermodynamics, (1982), 213-219.

[20]. Karpov I.K., Chudnenko K.V., Kulik D.A., Bychinskii V.A., "The convex programming minimization of five thermodynamic potential other than Gibbs energy in geochemical modeling”, Amer. J. Sci, 302, (2002), 281311 . 